\section{Rage gene promoter polymorphisms and diabetic retinopathy in a clinic-based population from South India}

S Ramprasad', V Radha', RA Mathias², PP Majumder ${ }^{3}$, MRS Rao $^{4}$ and M Rema ${ }^{1}$
Purpose The main objective of this study was to evaluate if the $-429 \mathrm{~T} / \mathrm{C},-374 \mathrm{~T} / \mathrm{A}$ and $63 \mathrm{bp}$ deletion polymorphisms in the RAGE gene are associated with diabetic retinopathy (DR) among Type 2 diabetic subjects in a clinicbased population from South India. Methods We screened 149 normal glucose tolerant subjects (NGT), 189 Type 2 diabetes subjects without retinopathy (DM) and 190 subjects with DR for these polymorphisms using the PCR-RFLP method. DR was diagnosed by grading color fundus photography. Logistic regression models were used to evaluate the association of individual polymorphisms with DR. Expectationmaximization algorithms were implemented in haplotype tests of association to examine the combined effects of $-429 \mathrm{~T} / \mathrm{C}$ and $-374 \mathrm{~T} / \mathrm{A}$ polymorphisms on DR.

Results The allelic frequencies of $-429 \mathrm{~T}$ are 0.83 in NGT, 0.84 in DM and 0.85 in DR subjects, and that of $-374 \mathrm{~T}$ are 0.93 in NGT, 0.92 in DM and 0.88 in DR subjects. The -374 polymorphism was found to be associated with non-proliferative retinopathy when this subgroup was compared to the DM group $(\mathrm{OR}=1.814,95 \% \mathrm{CI}=1.005-3.273)$. However, this association was not obvious when both the subphenotypes of DR (the nonproliferative and proliferative DR groups) were studied jointly. We found no evidence for associations between the $-429 \mathrm{~T} / \mathrm{C}$

polymorphism and the DR phenotype. Finally, extension to a 2-SNP haplotype did not reveal any significant statistical difference between the groups $(P=0.668)$.

Conclusion In this study, we found a modest association with the $-374 \mathrm{~T} / \mathrm{A}$ polymorphism in the nonproliferative DR subgroup.
Eye (2007) 21, 395-401. doi:10.1038/sj.eye.6702239; published online 27 January 2006

Keywords: diabetic retinopathy; RAGE polymorphism; -374 TA; -429 TC; $63 \mathrm{bp}$ deletion

\section{Introduction}

In individuals with diabetes, nonenzymatic glycation of proteins leads to the formation of advanced glycation end products (AGE) and this process occurs at an accelerated rate in chronic hyperglycaemia ${ }^{1}$, and also the levels are found to be increased in complications of diabetes, such as diabetic retinopathy (DR). ${ }^{2}$ AGE induces a variety of pathological changes, such as increased basement membrane thickening, arterial stiffness, and glomerular sclerosis. ${ }^{3,4}$ AGEs bind to a specific receptor known as receptor for advanced glycation end products (RAGE). RAGE is expressed in many of the cell types, such as the endothelial cells, monocytes, and lymphocytes, including the beta cells of the pancreas. RAGE-mediated signaling leads to the activation of transcription factors, such as NF- $\kappa$ B, AP-1, and STAT- 1, , 6 the adhesion molecules VCAM, ICAM, and tissue factor, ${ }^{7,8}$ which promote a procoagulant state in the microcapillaries of the retina. This results in a hypoxic state that leads to the initiation of the angiogenic process in proliferative DR.

The involvement of genetic factors in the pathogenesis of DR has been supported by studies that have demonstrated the familial clustering of DR.9,10 Earlier studies performed by Rema et $a l^{11}$ in a South Indian population have shown that siblings of subjects with DR were 3.5 times more likely to develop DR
${ }^{1}$ Madras Diabetes Research Foundation \& Dr Mohan's Diabetes Specialities Centre Gopalapuram, Chennai, India

${ }^{2}$ Genometrics Section, Inherited Disease Research Branch, National Human Genome Research Institute, National Institutes of Health, Baltimore, MD, USA

${ }^{3}$ Indian Statistical Institute, Kolkata, India

${ }^{4}$ Department of Biochemistry, Indian Institute of Science, Bangalore, India

Correspondence: M. Rema, Madras Diabetes Research Foundation, 4, Conran Smith Road, Gopalapuram, Chennai, 600 086, India Tel: + 91442835 9050; Fax: + 914428350935. E-mail: drrema@ vsnl.com

Received: 27 May 2005 Accepted in revised form: 28 November 2005; Published online: 27 January 2006 
compared to siblings of subjects without DR, suggesting a strong genetic component associated with the development of DR in this population. Various candidate genes have been tested for their association with DR, which includes aldose reductase, ${ }^{12,13}$ nitric oxide synthase, ${ }^{14,15}$ and MethylTetra Hydro Folate Reductase ${ }^{16}$ that have had conflicting reports in various populations. Among many candidate genes that have been found to be associated with retinopathy, the gene encoding RAGE is of particular significance, because the RAGE-mediated signaling induces key pathological changes in the microvasculature leading to DR. A functional polymorphism Gly82Ser in exon 3 has been previously implicated in DR of which the Ser allele of this Gly82Ser polymorphism has been shown to be protective in the development of DR in the Asian-Indian population. ${ }^{17}$ Studies performed by Hudson et $a l^{18}$ have shown that three polymorphisms located in the promoter region (-429TC and -374TA and $63 \mathrm{bp} \mathrm{del)}$ of the RAGE gene are involved in the upregulation of the gene and thereby could play a pivotal role in the pathogenesis leading to DR. The $63 \mathrm{bp}$ deletion polymorphism is in the region encompassing the -374 region, and these promoter polymorphisms exert their effect by affecting the transcriptional regulation of the RAGE gene. The association of these promoter polymorphisms has been studied in various populations with respect to DR and other diseases, but the results are conflicting. ${ }^{19-21}$ Although Indians have the largest number of diabetic patients in the world, ${ }^{22,23}$ there is a paucity of literature on the genetic factors contributing to DR in Indians. In this study, we have examined $-429 \mathrm{TC}$ and $-374 \mathrm{TA}$ promoter polymorphisms in relation to DR in South Indian Type 2 diabetic subjects.

\section{Subjects and methods}

Three classes of study subjects were included as described below. The first group referred to as the ' $D R$ ' group comprised of 190 diabetic subjects with any form of retinopathy including (1) 133 nonproliferative diabetic retinopathy (NPDR) subjects who had only NPDR without diabetic macular oedema, duration of diabetes $>10$ years, and macroproteinuria $<300 \mathrm{mg} /$ day, and (2) 57 proliferative diabetic retinopathy (PDR) subjects with macroproteinuria $<300 \mathrm{mg} /$ day. The second group referred to as the ' $D M$ ' group consisted of 189 Type 2 diabetic subjects with a disease duration of $>15$ years, and free from retinopathy and nephropathy. The ' $N G T^{\prime}$ group consisted of 149 normal glucose tolerant subjects (NGT) over the age of 50 (thereby giving adequate time to develop DM). Type 2 diabetic subjects with and without DR for these first two categories were recruited from patients who attended the out-patient clinic at the
Dr Mohan's Diabetes Specialties Centre. To circumvent the problem of population stratification, we performed a case-control study at five unlinked marker loci believed to be unrelated to the disease under study, but known to have allelic diversity among different populations. ${ }^{24,25}$ The allele frequency difference between DM, DR, and NGT subjects was not statistically significant at any of the five loci.

To examine the association of polymorphisms in the RAGE gene with DR, the main focus was to compare the DR group consisting of NPDR and PDR subgroups both individually and combined to the DM group, and to further elucidate the role of these variants in Type 2 diabetes, the DM group was also compared with the NGT group. Further comparison of the DR groups (both individually and combined) to the NGT group was also performed. Considering the association reported by Hudson et al $^{18}$ along with our sample size, our study would have had a power of $91 \%$ to detect a similar association.

Informed consent was obtained from all study subjects as per the protocol approved by the Madras Diabetes Research Foundation Institutional Ethics Review Board.

\section{Biochemical estimations}

A fasting blood sample was taken and serum separated and stored at $-70^{\circ} \mathrm{C}$ until the assays were performed. Biochemical analyses were performed on a Hitachi-912 Autoanalyser (Hitachi, Germany) using kits supplied by Roche Diagnostics (Mannheim, Germany). Fasting plasma glucose (GOD-POD method), serum cholesterol (CHOD-PAP method), serum triglycerides (GPO-PAP method), and HDL cholesterol (Direct methodpolyethylene glycol-pretreated enzymes) were measured. Low-density lipoprotein (LDL) cholesterol was calculated using the Friedewald formula. ${ }^{26}$ Glycated haemoglobin (HbA1C) was estimated by highperformance liquid chromatography using the Variant machine (Bio-Rad, Hercules, CA, USA).

Urine samples were collected in the early morning after an overnight fast. Urinary protein was measured on spot urine by sulphosalicylic acid technique. Expected protein excretion was calculated by the protein/ creatinine ratio method and overt proteinuria was defined as $\geq 300 \mathrm{mg} /$ day. $^{27}$

\section{DR diagnosis}

DR was diagnosed by retinal examination and documented by $35 \mathrm{~mm}$ colour photography. For retinal examination, the pupils were dilated by instilling one drop each of phenylephrine $10 \%$ and tropicamide $1 \%$ in both eyes, and the drops were repeated until the best 
possible mydriasis was obtained. Four-field colour retinal photography was carried out by a trained photographer with a Zeiss FF 450 plus camera using $35 \mathrm{~mm}$ colour transparencies. The four fields taken were stereoscopic pictures of the macula, disc, superior temporal, and inferior temporal quadrants. If photography of a particular eye or any field was not possible due to inadequate dilatation, inability to cooperate or opacities of the media, these were specified as missing eye or fields.

Grading of retinal photographs were performed using an identification number and assessed in a masked manner in order to minimize any possible bias. The photographs were graded for severity of retinopathy against standard photographs of the Early Treatment Diabetic Retinopathy Study (ETDRS) grading system. ${ }^{28}$ The eye with the higher grade of retinopathy was taken as the final diagnosis for that individual.

\section{PCR-RFLP}

Human genomic DNA was extracted using the phenolchloroform method. PCR-RFLP genotyping was carried out as described. ${ }^{18}$ PCR consisted of 100-150 ng of DNA denaturing at $94^{\circ} \mathrm{C}$, annealing at $56^{\circ} \mathrm{C}$, extension at $72^{\circ} \mathrm{C}$ for 30 cycles, followed by a final extension at $72^{\circ} \mathrm{C}$ for $5 \mathrm{~min}$ in a $50 \mu \mathrm{l}$ reaction. The PCR products were then digested with Alu I (New England Bio Labs) at $37^{\circ} \mathrm{C}$ for $6 \mathrm{~h}$ for $-429 \mathrm{~T} / \mathrm{C}$ polymorphism and Tsp509 I (New England Bio Labs) at $65^{\circ} \mathrm{C}$ for $16 \mathrm{~h}$ for $-374 \mathrm{~T} / \mathrm{A}$ polymorphism. ${ }^{18}$ The restricted products were separated in a $3 \%$ agarose gel and visualized using ethidium bromide staining.

\section{Statistical analysis}

For this case-control study design, independent sample $t$-tests were used to evaluate differences in the quantitative traits between the various study groups using the SPSS computer program (version 10). Traits were log transformed to approximate a Gaussian distribution where required, and adjusted for the covariates of age and sex as necessary. Allele and genotype frequencies, logistic regressions for odds ratios (OR), and $\chi^{2}$ tests were evaluated to test for associations at the single SNP level. Hardy Weinberg equilibrium was evaluated using $\chi^{2}$ tests (in Excel 2003), and linkage disequilibrium was evaluated using Haploview. ${ }^{29}$ Groupwise haplotype frequencies were generated using the expectation-maximization (EM) algorithm as described by Fallin et al. ${ }^{30}$ Haplotype frequencies and $\chi^{2}$ values were calculated for each individual haplotype $v s$ all others, and empiric significance was assessed using 10000 permutations of the observed data. The 'omnibus test' was also performed to detect differences in overall haplotype frequency profiles between case-control groups. ${ }^{30}$ The haplotype analyses were performed using SNPEM. ${ }^{30}$

\section{Results}

We screened the promoter region of the RAGE gene for two functional promoter polymorphisms, namely the

Table 1 Comparison of clinical features between normal glucose tolerant subjects (NGT), diabetic subjects with retinopathy (DR), and diabetic subjects without retinopathy (DM)

\begin{tabular}{|c|c|c|c|c|}
\hline \multirow[b]{2}{*}{ Clinical characteristics } & \multirow[b]{2}{*}{$N G T \mathrm{n}=149$} & \multirow[b]{2}{*}{$D M \mathrm{n}=189$} & \multicolumn{2}{|c|}{$D R$} \\
\hline & & & $N P D R \mathrm{n}=133$ & $P D R \mathrm{n}=57$ \\
\hline Age in years & $59(8)$ & $63(9)^{* * *}$ & $59(8)^{\# \# \#}$ & $59(8)^{\# \# \#}$ \\
\hline Males $(n, \%)$ & $77(52 \%)$ & $131(69 \%)^{* *}$ & $65(49 \%)^{\# \# \#}$ & $40(70 \%)^{\# \# \#}$ \\
\hline Duration in years & - & $21(5)$ & $20(6)$ & $20(8)$ \\
\hline $\mathrm{HbA} 1 \mathrm{C}$ as $\%$ & $5.8(0.5)$ & $8.1(1.6)^{* * *}$ & $8.6(1.9)^{* * *, \#}$ & $8.9(1.7)^{* * *, \#}$ \\
\hline FBS (mg/dl) & $86(10)$ & $154(60)^{* * *}$ & $167(68)^{* * *}$ & $161(61)^{* * *}$ \\
\hline PPBS (mg/dl) & - & $234(85)$ & $248(76)$ & $242(82)$ \\
\hline $\mathrm{SBP}(\mathrm{mmHg})^{\mathrm{a}}$ & $126(19)$ & $133(15)^{*}$ & $137(18)^{* * *, \#}$ & $139(17)^{* * * * \#}$ \\
\hline DBP $(\mathrm{mmHg})^{\mathrm{b}}$ & 77 (10) & $80(11)$ & $82(14)$ & $84(22)$ \\
\hline Cholesterol $(\mathrm{mg} / \mathrm{dl})^{\mathrm{a}}$ & $190(37)$ & $184(37)$ & $189(53)$ & $178(47)$ \\
\hline Triglycerides $(\mathrm{mg} / \mathrm{dl})^{\mathrm{a}, \mathrm{b}}$ & 115 (55) & $147(95)^{* * *}$ & $178(126)^{* * *}$ & $139(72)^{* * *}$ \\
\hline
\end{tabular}

Unless otherwise stated, values are represented as mean (SD).

${ }^{*} P<0.05,{ }^{* *} P<0.01,{ }^{* * *} P<0.001$ when compared with nondiabetic subjects.

${ }^{\#} P<0.05,{ }^{\# \#} P<0.01,{ }^{\# \#} P<0.001$ when compared with diabetic subjects.

${ }^{\text {a } D a t a}$ adjusted for age and/or gender.

bStatistical analysis was performed on log transformed data.

$\mathrm{FBS}=$ fasting blood sugar; $\mathrm{PPBS}=$ postprandial blood sugar; $\mathrm{SBP}=$ systolic blood pressure; $\mathrm{DBP}=$ diastolic blood pressure 
$-429 \mathrm{~T} / \mathrm{C}$ and $-374 \mathrm{~T} / \mathrm{A}$, in 529 unrelated subjects of South Indian origin. The clinical characteristics of the three study groups are shown in Table 1. Age, HbA1C, fasting blood sugar, systolic blood pressure, and triglycerides were significantly associated with diabetes (comparing the DR and DM groups to the NGT group). Systolic blood pressure, $\mathrm{HbA1C}$, and male gender were nominally associated with DR $(P<0.05$ comparing the $D R$ group to the $D M$ group), and the $D M$ subjects were significantly older $(P<0.001)$.

The overall minor allele frequency in all study subjects was $16 \%$ for the $-429(\mathrm{C})$ polymorphism and $9 \%$ for the -374(A) polymorphism. Both SNPs were in Hardy Weinberg equilibrium, and linkage disequilibrium (LD) between them was moderate $\left(D^{\prime}=0.74, R^{2}=0.02,95 \% \mathrm{CI}\right.$ for $\left.D^{\prime}: 0.27-0.93\right)$. The two individual SNPs were not associated with DR or diabetes at the allelic level: $P$-value for DM vs NGT was 0.729 , for DR vs DM was 0.101 , and DR vs NGT was 0.064 for $-374 \mathrm{~T} / \mathrm{A}$, and $0.719,0.668$,
0.444 for the same three comparisons for $-429 \mathrm{~T} / \mathrm{C}$, respectively.

In the evaluation of associations at the genotype level, the rare homozygous group was collapsed with the heterozygous group for both polymorphisms (Table 2). Subjects with the $63 \mathrm{bp}$ deletion were first excluded from these genotype analyses for the $-374 \mathrm{~T} / \mathrm{A}$ polymorphism, as all these individuals had only a single copy of this polymorphism. Only a marginal association was observed for the $-374 \mathrm{~T} / \mathrm{A}$ polymorphism in the comparison of the NPDR subjects to the DM group (OR $=1.814, P=0.048,95 \%$ $\mathrm{CI}=1.005-3.273)$, and no association was detected comparing the PDR and DM groups $(\mathrm{OR}=0.990$, $P=0.982,95 \% \mathrm{CI}=0.419-2.336$ ). No associations were detected for the $-429 \mathrm{~T} / \mathrm{C}$ polymorphisms (Table 2). Tests of association were repeated adjusting for age and gender, and no difference was observed even after adjustment. Subsequent comparison of these groups to

Table 2 Association between the -429 and -374 promoter polymorphisms in the RAGE gene and diabetic retinopathy at the genotype level

\begin{tabular}{|c|c|c|c|c|c|}
\hline \multirow[b]{2}{*}{ Genotype } & \multirow[b]{2}{*}{$N G T \mathrm{~N}=149$} & \multirow[b]{2}{*}{$D M \mathrm{~N}=189$} & \multicolumn{3}{|c|}{$D R$} \\
\hline & & & $A L L D R \mathrm{~N}=190$ & $N P D R \mathrm{~N}=133$ & $P D R \mathrm{~N}=57$ \\
\hline \multicolumn{6}{|c|}{-374 T/A Polymorphism } \\
\hline TT & $117(79 \%)$ & $148(78 \%)$ & $137(72 \%)$ & $91(68 \%)$ & $46(81 \%)$ \\
\hline TA & $20(13 \%)$ & $24(13 \%)$ & $33(17 \%)$ & $26(20 \%)$ & $7(12 \%)$ \\
\hline $\mathrm{AA}^{\mathrm{a}}$ & 0 & $2(1 \%)$ & $4(2 \%)$ & $3(2 \%)$ & $1(2 \%)$ \\
\hline \multirow[t]{2}{*}{$63 \mathrm{bp}$ del } & $12(8 \%)$ & $15(8 \%)$ & $16(8 \%)$ & $13(10 \%)$ & $3(5 \%)$ \\
\hline & Odds ratio ${ }^{\mathrm{b}}$ & & $95 \%$ confidence interval & & P-value \\
\hline NPDR vs $\mathrm{DM}_{r e f}$ & 1.814 & & $1.005-3.273$ & & 0.048 \\
\hline PDR vs $\mathrm{DM}_{r e f}$ & 0.990 & & $0.419-2.336$ & & 0.982 \\
\hline $\mathrm{DR}$ vs $\mathrm{DM}_{r e f}$ & 1.537 & & $0.885-2.672$ & & 0.127 \\
\hline $\mathrm{DM}$ vs $\mathrm{NGT}_{r e f}$ & 1.028 & & $0.547-1.932$ & & 0.932 \\
\hline $\mathrm{DR} v s \mathrm{NGT}_{r e f}$ & 1.580 & & $0.869-2.871$ & & 0.133 \\
\hline NPDR vs $\mathrm{NGT}_{r e f}$ & 1.864 & & $0.991-3.508$ & & 0.053 \\
\hline PDR vs $\mathrm{NGT}_{r e f}$ & 1.017 & & $0.419-2.473$ & & 0.970 \\
\hline \multicolumn{6}{|c|}{-429 T/C Polymorphism } \\
\hline TT & $97(65 \%)$ & $130(69 \%)$ & $132(69 \%)$ & $95(71 \%)$ & $37(65 \%)$ \\
\hline $\mathrm{TC}$ & $52(35 \%)$ & $56(30 \%)$ & $58(31 \%)$ & $38(29 \%)$ & $20(35 \%)$ \\
\hline \multirow[t]{2}{*}{$\mathrm{CC}^{\mathrm{a}}$} & 0 & $3(1 \%)$ & 0 & 0 & 0 \\
\hline & Odds ratio ${ }^{\mathrm{b}}$ & & $95 \%$ confidence interval & & $\mathrm{P}-$ value \\
\hline NPDR vs $\mathrm{DM}_{r e f}$ & 0.881 & & $0.542-1.433$ & & 0.611 \\
\hline PDR vs $\mathrm{DM}_{r e f}$ & 1.191 & & $0.637-2.225$ & & 0.584 \\
\hline $\mathrm{DR}$ vs $\mathrm{DM}_{r e f}$ & 0.968 & & $0.626-1.497$ & & 0.884 \\
\hline $\mathrm{DM}$ vs $\mathrm{NGT}_{r e f}$ & 0.847 & & $0.536-1.336$ & & 0.474 \\
\hline $\mathrm{DR} v s \mathrm{NGT}_{r e f}$ & 0.820 & & $0.519-1.294$ & & 0.394 \\
\hline NPDR vs $\mathrm{NGT}_{r e f}$ & 0.746 & & $0.450-1.236$ & & 0.256 \\
\hline $\mathrm{PDR}$ vs $\mathrm{NGT}_{r e f}$ & 1.008 & & $0.532-1.912$ & & 0.980 \\
\hline
\end{tabular}

Percentages reflect column totals. $r e f=$ Reference baseline group.

a Homozygote of the minor allele was collapsed with the heterozygote due to small sample sizes (TT is the baseline group)

'Subjects with the $63 \mathrm{bp}$ deletion were excluded from this analysis.

${ }^{\mathrm{c}}$ Tests of association were repeated adjusting for age and gender, and no difference was observed even after adjustment. 
Table 3 Association analysis of haplotypes constructed across the -374 and -429 polymorphisms for diabetic retinopathy

\begin{tabular}{lccc}
\hline -374/-429 Haplotype & DR $(\%)$ & DM (\%) & P-value $^{*}$ \\
\hline T-T & 74 & 76 & 0.270 \\
C-T & 15 & 16 & 0.624 \\
T-A & 10 & 8 & 0.232 \\
C-A & 1 & 0.3 & 0.874
\end{tabular}

Omnibus $P$-value ${ }^{* *}=0.668$

${ }^{*} P$-value for each haplotype vs all others combined, ${ }^{* *}$ omnibus $P$-value for the overall test of association.

the NGT group revealed no evidence for association (see Table 2). Extension to the two-SNP haplotype also showed no association between these promoter polymorphisms and the DR phenotype in our data $(P=0.668)$ (Table 3).

The $63 \mathrm{bp}$ deletion polymorphism was found only in the heterozygous state in all the study subjects when present. This $63 \mathrm{bp}$ deletion polymorphism was also found to be similar in all the three groups, which were present in 12 NGT, $15 \mathrm{DM}$, and $16 \mathrm{DR}$ subjects. We examined the effect of this $63 \mathrm{bp}$ deletion in the genotype and haplotype analyses by coding all subjects with the deletion as heterozygous at the -374 polymorphism. Here, the genotype analysis once again provided only marginal evidence in the comparison of the NPDR and $\mathrm{DM}$ groups $(\mathrm{OR}=1.666, P=0.047,95 \% \mathrm{CI}=$ 1.007-2.756), but there was no evidence for any association with DR at the haplotype level $(P=0.589$, data not shown).

\section{Discussion}

The AGE-RAGE pathway has been extensively studied in the context of diabetic vascular disease. Variations in the RAGE gene have been identified and screened for association with DR and other diseases. ${ }^{31-33}$ Of the many polymorphisms that have been screened, the -429 and -374 are considered important, since these polymorphisms are reported to increase the RAGE gene transcript, which will augment increased AGE binding to cells and as a result lead to an altered signaling cascade. The G82S polymorphism has also been studied in various populations, which is yet another important polymorphism previously studied in this population. ${ }^{17}$ Here, we screened for the first time the -429 and -374 promoter polymorphisms to look for their association with DR in South Indian subjects.

As expected, several of the biochemical parameters assayed showed significant differences between the study groups, including age, HbA1c, fasting blood sugar, systolic blood pressure, and triglycerides. The difference in age is due to our selection criteria for DM subjects, which necessitates a 15-year duration of diabetes without any form of retinopathy. The other clinical parameters with significant differences are well-established risk factors for the development of DR.

Association results from studies performed on the -374 and -429 RAGE polymorphisms have not been consistent between different populations. Although studies in UK-based Caucasian populations have associated the $-429 \mathrm{~T} / \mathrm{C}$ polymorphism with retinopathy ${ }^{13}$ and the -374 polymorphism with CAD and proteinuria in Finnish Type 1 diabetic subjects, ${ }^{19}$ we did not find evidence for association of DR with either the $-429 \mathrm{~T} / \mathrm{C}$ or the $-374 \mathrm{~T} / \mathrm{A}$ polymorphism in our data, despite a larger sample size with adequate power to detect associations at the reported levels. Upon stratifying the DR subjects into NPDR and PDR groups, while we observed association with the $-374 \mathrm{~T} / \mathrm{A}$ polymorphism for the NPDR group, this was marginally significant $(P=0.048)$, and hence should be interpreted with caution, especially considering the multiple tests carried out as part of these analyses. However, glycation is a process that takes place when diabetes sets in and the modified proteins bind to the RAGE on the retinal endothelial cells. This triggers a signaling cascade, leading to the release of proinflammatory cytokines and adhesion proteins that favour thrombosis and eventually capillary leakage and occlusion resulting in NPDR. In this context, this -374 polymorphism assumes significance given the induction of the RAGE gene by AGE.

Given the presence of LD between these polymorphisms as has been reported in other studies as well, ${ }^{18,19}$ we also performed haplotype tests for association which also yielded no evidence for association. In this study, we also compared the allele frequencies between the nondiabetics and the DM group, and also found them to be similar.

In conclusion, our results show an association of -374 $\mathrm{T} / \mathrm{A}$ polymorphism with NPDR, which is inconsistent to the Slovakian study, and the Chinese study which did not show any association between these promoter polymorphisms and DR. ${ }^{20,21}$ Other RAGE gene polymorphisms such as G82S, G1704T, A2484G, and G2245A, which have been studied extensively in different populations, ${ }^{32-37}$ need to be studied in this population to understand the impact of these variations on the onset and progression of DR. Ethnic variations, if any, that may have been present in the study subjects were tested using genomic controls that did not show allele frequency variation among the groups, suggesting strongly that these results are not an artefact due to population substructuring. Studies on the RAGE protein expression in the retinal endothelial 
cells and the serum measurement of AGE levels in these patients will give further insight into the influence of AGE interaction with this promoter polymorphism leading to vascular complications of diabetes.

\section{Acknowledgements}

This study was supported by a Grant from the Department of Biotechnology (DBT), New Delhi, India. This research was supported in part by the Intramural Research Program of the National Human Genome Research Institute, National Institutes of Health. The authors are also thankful to Ms P Gayathri for her help in recruiting the study subjects. The authors take responsibility for the integrity of the data and the accuracy of the data analysis.

\section{References}

1 Ceramin A, Vlassara H, Brownlee M. Role of AGE's in complications of diabetes. Diabetes Care 1988; 11: 73-79.

2 Sampathkumar R, Balasubramanyam M, Premanand C, Rema M, Mohan V. Novel Advanced Glycation Index (AGI) and its association with diabetes and Microangiopathy. Metabolism 2005; 54(8): 1002-1007.

3 Brownlee M, Cerami A, Vlassara H. Advanced glycosylation end products in tissue and the biochemical basis of diabetic complications. N Engl J Med 1988; 318(20): 1315-1321.

4 Horie K, Miyata T, Maeda K, Miyata S, Sugiyanma S, Sakai $\mathrm{H}$ et al. Immunohistochemical colocalization of glycoxidation products and lipid peroxidation products in diabetic renal glomerular lesions. Implication for glycoxidative stress in the pathogenesis of diabetic nephropathy. J Clin Invest 1997; 100: 2995-3004.

5 Bierhaus A, Chevion S, Chevion M, Hofmann M, Quehenberger P, Illmer T et al. Advanced glycation end products AGEs induced activation of NF- $\kappa$ B is suppressed by $\alpha$-lipoic acid in cultured endothelial cells. Diabetes 1997; 46: 1481-1490.

6 Huang JS, Guh JY, Hung WC, Yang ML, Lai YH, Chen HC et al. Role of the Janus kinase (JAK)/signal transducters and activators of transcription (STAT) cascade in advanced glycation end-product-induced cellular mitogenesis in NRK-49F cells. Biochem J 1999; 342(Part1): 231-238.

7 Vlassara H, Fuh H, Donnelly T, Cybulsky M. Advanced glycation endproducts promote adhesion molecule VCAM1, ICAM-1 expression and atheroma formation in normal rabbits. Mol Med 1995; 1: 447-456. 196.

8 Bierhaus A, Illmer T, Kasper M, Luther T, Quehenberger P, Tritschler $\mathrm{H}$ et al. Advanced glycation endproducts AGEs mediated induction of tissue factor in cultured endothelial cells is dependent on RAGE. Circulation 1997; 96: 2262-2271.

9 The Diabetes Control and Complications Trial Research Group. Clustering of long-term complications in families with diabetes in the diabetes control and complications trial. Diabetes 1997; 46(11): 1829-1839.

10 Pyke DA, Tattersall RB. Diabetic retinopathy in identical twins. Diabetes 1972; 22: 613-618.
11 Rema M, Saravanan G, Deepa R, Mohan V. Familial clustering of diabetic retinopathy in South Indian Type 2 diabetic patients. Diabet Med 2002; 19(11): 910-916.

12 Santos KG, Tschiedel B, Schneider J, Souto K, Roisenberg I. Diabetic retinopathy in Euro-Brazilian type 2 diabetic patients: relationship with polymorphisms in the aldose reductase, the plasminogen activator inhibitor- 1 and the methylenetetrahydrofolate reductase genes. Diabetes Res Clin Pract 2003; 61(2): 133-136.

13 Kumaramanickavel G, Sripriya S, Ramprasad VL, Upadyay NK, Paul PG, Sharma T. Z-2 aldose reductase allele and diabetic retinopathy in India. Ophthalmic Genet 2003; 24(1): $41-48$.

14 Taverna MJ, Elgrably F, Selmi H, Selam JL, Slama G. The T-786C and C774T endothelial nitric oxide synthase gene polymorphisms independently affect the onset pattern of severe diabetic retinopathy. Nitric Oxide 2005; 13(1): 88-92.

15 Fujita H, Narita T, Meguro H, Ishii T, Hanyu O, Suzuki K et al. Lack of association between an ecNOS gene polymorphism and diabetic nephropathy in type 2 diabetic patients with proliferative diabetic retinopathy. Horm Metab Res 2000; 32(2): 80-83.

16 Zintzaras E, Chatzoulis DZ, Karabatsas CH, Stefanidis I. The relationship between C677T methylenetetrahydrofolate reductase gene polymorphism and retinopathy in type 2 diabetes: a meta-analysis. J Hum Genet 2005; 50(6): 267-275. E-pub 2005 May 18.

17 Kumaramanickavel G, Ramprasad VL, Sripriya S, Upadyay NK, Paul PG, Sharma T et al. Association of Gly82Ser polymorphism in the RAGE gene with diabetic retinopathy in type II diabetic Asian Indian patients. J Diabetes Complications 2002; 16(6): 391-394.

18 Hudson BI, Stickland MH, Futers TS, Grant PJ. Effects of novel polymorphisms in the RAGE gene on transcriptional regulation and their association with diabetic retinopathy. Diabetes 2001; 50(6): 1505-1511.

19 Pettersson-Fernholm K, Forsblom C, Hudson BI et al. Finn-Diane Study Group. The functional -374 T/A RAGE gene polymorphism is associated with proteinuria and cardiovascular disease in type 1 diabetic patients. Diabetes 2003; 52(3): 891-894.

20 Globocnik Petrovic M, Steblovnik K, Peterlin B et al. The $-429 \mathrm{~T} / \mathrm{C}$ and $-374 \mathrm{~T} / \mathrm{A}$ gene polymorphisms of the receptor of advanced glycation end products gene are not risk factors for diabetic retinopathy in Caucasians with type 2 diabetes. Klin Monatsbl Augenheilkd 2003; 220(12): 873-876.

21 JiXiong X, BiLin X, MingGong Y, ShuQin L. -429T/C and $-374 \mathrm{~T} / \mathrm{A}$ polymorphisms of RAGE gene promoter are not associated with diabetic retinopathy in Chinese patients with type 2 diabetes. Diabetes Care 2003; 26(9): 2696-2697.

22 King H, Aubert R, Herman W. Global burden of diabetes, 1995-2025. Prevalence, numericalestimates and projections. Diabetes Care 1998; 21: 1414-1431.

23 Wild S, Roglic G, Green A, Sicree R, King H. Global prevalence of diabetes: estimates for the year 2000 and projections for 2030. Diabetes Care 2004; 27(5): 1047-1053.

24 Basu A, Mukherjee N, Roy S, Sengupta S, Banerjee S, Chakraborty $\mathrm{M}$ et al. Ethnic India: a genomic view, with special reference to peopling and structure. Genome Res 2003; 13: 2277-2290.

25 Devlin B, Roeder K, Wasserman L. Genomic control, a new approach to genetic-based association studies. Theor Popul Biol 2001; 60: 155-166. 
26 Friedewald WT, Levy RI, Fredrickson DS. Estimation of low density lipoprotein cholesterol without the use of the preparative ultracentrifuge. Clin Chem 1972; 18: 499-502.

27 Varghese A, Deepa R, Rema M, Mohan V. Prevalence of microalbuminuria in Type 2 diabetes mellitus at a diabetes centre in Southern India. Postgraduate Med J 2001; 77: 399-402.

28 Early Treatment of Diabetic Retinopathy Study Research Group. Grading diabetic retinopathy from stereoscopic colour fundus photographs - an extension of the modified Airlie House Classification. ETDRS Report 10. Ophthalmology 1991; 98: 786-806.

29 Barrett JC, Fry B, Maller J, Daly MJ. Haploview: analysis and visualization of LD and haplotype maps. Bioinformatics 2005; 21: 263-265.

30 Fallin D, Schork NJ. Accuracy of haplotype frequency estimation for biallelic loci, via the expectationmaximization algorithm for unphased diploid genotype data. Am J Hum Genet 2000; 67: 947-959.

31 Poirier O, Nicaud V, Vionnet N, Raoux S, Tarnow L, Vlassara $\mathrm{H}$ et al. Polymorphism screening of four genes encoding advanced glycation end-product putative receptors. Association study with nephropathy in type 1 diabetic patients. Diabetes 2001; 50(5): 1214-1218.

32 Falcone C, Campo I, Emanuele E, Buzzi MP, Geroldi D, Belvito $\mathrm{C}$ et al. $-374 \mathrm{~T} / \mathrm{A}$ polymorphism of the RAGE gene promoter in relation to severity of coronary atherosclerosis. Clin Chim Acta 2005; 354(1-2): 111-116. E-pub 2005 Jan 13.
33 Holla LI, Kankova K, Fassmann A, Buckova D, Halabala T, Znojil V et al. Distribution of the receptor for advanced glycation end products gene polymorphisms in patients with chronic periodontitis: a preliminary study. J Periodontol 2001; 72(12): 1742-1746.

34 Prevost G, Fajardy I, Besmond C, Balkau B, Tichet J, Fontaine $\mathrm{P}$ et al. The Genediab and D.E.S.I.R studies. Polymorphisms of the receptor of advanced glycation endproducts (RAGE) and the development of nephropathy in type 1 diabetic patients. Diabetes Metab 2005; 31(1): 35-39.

35 Yoshioka K, Yoshida T, Takakura Y, Umekawa T, Kogure A, Toda $\mathrm{H}$ et al. Association study of G1704T and G82S polymorphisms of RAGE gene for microalbuminuria in Japanese type 2 diabetic patients. Metabolism 2005; 54(4): 488-491.

36 Kankova K, Stejskalova A, Hertlova M, Znojil V. Haplotype analysis of the RAGE gene: identification of a haplotype marker for diabetic nephropathy in type 2 diabetes mellitus. Nephrol Dial Transplant 2005; 20(6): 1093-1102. E-pub 2005 Mar 24.

37 Matsunaga-Irie S, Maruyama T, Yamamoto Y, Motohashi Y, Hirose H, Shimada A et al. Relation between development of nephropathy and the p22phox C242T and receptor for advanced glycation end product G1704T gene polymorphisms in type 2 diabetic patients. Diabetes Care 2004; 27(2): 303-307. 